\title{
Self-regulation of neutrophils during phagocytosis is modified after severe tissue injury
}

\author{
GÁBOR PAP ${ }^{1}$, JÓZSEF FûRÉSZ ${ }^{2}$, JÁNOS FENNT² ${ }^{2}$ GÁBOR C. KOVÁCS ${ }^{4}$, \\ LÁSZLÓ NAGY ${ }^{3}$ and JÁNOS HAMAR ${ }^{1}$ \\ ${ }^{1}$ National Institute of Traumatology, Fiumei út 17, H-1081 Budapest; ${ }^{2}$ National Institute of Health Protection, \\ Hungarian Defence Forces; ${ }^{3}$ Central Military Hospital, ICU, Róbert Károly krt. 44, H-1134 Budapest; \\ ${ }^{4}$ Semmelweis University, First Clinic of Surgery, Üllöi út 78, H-1082 Budapest, Hungary
}

Received March 19, 2004; Accepted August 16, 2004

\begin{abstract}
Neutrophil (PMNL) function is influenced by factors released by other immune cells during the course of the immune response. We investigated the effect of neutrophil cell density and the effect of supernatant of the phagocytosis assay on the phagocytosis activity of PMNLs. The measurements were carried out with naive (control) PMNLs of healthy donors and with PMNLs obtained from patients with severe tissue injury. Phagocytosis index (FI) of PMNLs was determined at cell densities of $7.5 \times 10^{5} / \mathrm{ml}$ and $15 \times 10^{5} / \mathrm{ml}$. E. coli phagocytosis of heparinized whole blood from healthy donors and patients with severe tissue injury was measured and evaluated at three different cell densities (normal, half, and double densities) by flow cytometry. Supernatants of phagocytosis assays of either control or trauma (ISS >18) patient PMNLs were added to the assay suspensions of control and trauma PMNLs. An increase in cell density of healthy donor PMNLs increased yeast phagocytic activity. In cases of tissue injury, PMNLs showed increased phagocytic activity at lower cell densities. E. coli phagocytosis was increased with the increase of cell density, and tissue injury PMNLs were more active at each cell concentration compared to naive cells. Polytrauma supernatants in most cases inhibited, while healthy supernatants mostly increased the yeast phagocytosis of healthy and trauma PMNLs. These results reinforce the idea that primed PMNLs in the presence of microbial agents produce factor(s) which inhibit some of the cell's antimicrobial functions contributing to immunedysfunction, while unprimed PMNLs produce factor(s) which facilitate antimicrobial countermeasure. These results also
\end{abstract}

Correspondence to: Dr Gábor Pap, National Institute of Traumatology, Fiumei út 17, H-1081 Budapest, Hungary

E-mail:papg.pra@axelero.hu

Key words: low cytometry, human, humoral, micro-environment, neutrophil, phagocytosis, PMNL, self-regulation, solubile factors, tissue injury demonstrate that reduced phagocytosis of tissue injury primed PMNLs is not due to cytoskeletal changes but to the humoral environment.

\section{Introduction}

Severe tissue injuries, like multiple trauma, acute pancreatitis or major operations almost immediately induce the activation of the immune system. Tissue damage activates first the humoral systems followed by the activation of tissue mastocytes, macrophages, granulocytes and thrombocytes by mediators released from the injured cells. Activation of the immune cells results in further mediator release which attracts a plethora of inflammatory cells to the site of injury (1-8).

While circulating leukocytes led by chemotactic factors adhere to and migrate into tissues, their local cell concentration may change and their contacts to the endothelium or to other tissue components and to each other may influence their functions. Finally, the functions of leukocytes are greatly determined by humoral agents excreted by various cell types in the given micro-environment of the invaded tissue (9). Components of this micro-environment are also the solubile factors that are released by the activated neutrophils. The cell density of the present PMNLs therefore corresponds with the amount of solubile factors released and respectively whether these factors have a facilitating or inhibitory effect on various neutrophil functions, the PMNL density in the tissue itself may influence PMNL function $(10,11)$. However, these functions cannot be measured easily, hence their modelling is only partly possible (12-16). Only a few studies have been made to analyze the effect of neutrophils on each others' functions at different cell densities (17-21).

Polymorphonuclear leukocytes (PMNLs) have a major role in the elimination of pathogenes and also in the development of SIRS and MODS $(22,23)$. In SIRS and MODS neutrophils may fail to eliminate pathogens compared to what is expected under healthy conditions, although they release large amounts of oxygen free radicals and destructive enzymes.

In our current investigation we studied two models of phagocytosis. For the first setting we chose the yeast phagocytosis assay, where due to the size of the inactivated yeast particles, the process of phagocytosis takes more time, 
and assumably more energy, than the engulfment of bacteria. In our pilot studies we have found that 30-60 min were sufficient for the control neutrophils to incorporate the yeast cells. During this interval autocrine/paracrine functions may have an effect (24). Starting from the hypothesis that the concentration of the released factors effect cell function correlating with the density of the releasing cells, our aim was to investigate how yeast phagocytosis by neutrophils from healthy subjects and patients with severe trauma or with acute pancreatitis varies in assays with different cell densities and, how yeast phagocytosis changes during the course of illness. We also examined whether neutrophils produce humoral factors during yeast phagocytosis that influence the phagocytosis of healthy neutrophils.

Esherichia coli, may also be a natural contributor to infective disease, and has often been used to study neutrophil function, with varying outcomes (24-28). In the Esherichia coli phagocytosis model 5-10 min of incubation is enough to measure neutrophil phagocytosis, which time may be insufficient for the factors to alter cell function that are released during phagocytosis. Therefore, in our second setting we tested whether varying cell densities in the samples have an effect on the Esherichia coli phagocytosis of neutrophils taken from healthy subjects and patients with different severe tissue injuries.

\section{Materials and methods}

\section{Subject selection}

Control group. Seventeen healthy volunteers (7 women and 10 men) were selected for control measurements. Their ages ranged from 20 to 67 years, none of them had taken any medication in the previous 2 days that was known to influence neutrophil function (pain killers, anti-inflammatory or antipyretic drugs). Blood $(10 \mathrm{ml})$ was taken from each subject in the morning hours.

Multiple trauma group. Sixteen patients (4 women and 12 men) with multiple trauma (ISS $>15$ ) were enrolled in the study within a 1-year period. Their age ranged from 21 to 60 years. None of the involved women were pregnant. Blood $(10 \mathrm{ml})$ was taken from the patients in the morning on the 1 st, 3rd and 14th days following trauma. Patients were treated according to the appropriate protocols of the hospital.

Acute pancreatitis group. Fourteen patients with the diagnosis of acute pancreatitis ( 3 women and 11 men) were selected within a 15-month period. Their age ranged from 29 to 77 years. Exclusion criteria were: childhood, pregnancy, history of recurrent acute pancreatitis within 3 months, chronic pancreatitis, trauma or operation associated to pancreatitis, the use of immune suppressive drugs including steroids in the previous 1 month. Blood $(10 \mathrm{ml})$ was taken from the patients in the morning on the 1st, 3rd and 10th days of their hospitalisation.

Knowing that age and gender have influence on immune functions, due to our limited possibilities we have included in our studies all patients with multiple trauma with ISS $>15$ and all patients with acute pancreatitis fulfilling the above exclusion criteria, regardless to age and gender $(11,25,27-31)$.
Separation of neutrophils. Blood $(10 \mathrm{ml})$ was collected in (Vacuette, Greiner) tubes containing 3.8\% Na-citrate as anticoagulant. Erythrocytes were sedimented by adding $1 \mathrm{ml} 6 \%$ Dextrane T-500 (Pharmacia) solution for $30 \mathrm{~min}$ in a $37^{\circ} \mathrm{C}$ water bath. The buffy coat was centrifuged (200 g, $10 \mathrm{~min})$, the white blood cells were suspended in PBS, layered onto Ficoll-Paque (Pharmacia) and centrifuged (800 g, $20 \mathrm{~min}$ ). The remaining erythrocytes were lyzed by suspending the cells in destilled water for $45 \mathrm{sec}$ followed by the addition of the same volume of $1.8 \% \mathrm{NaCl}$ to normalise the osmotic pressure. Cells were washed three times and suspended in RPMI (Pharmacia) culture medium. Cell viability was assessed by tripan-blue exclusion test and only the suspensions with at least $95 \%$ viability were accepted for further examination. Cell density was set to $6 \times 10^{6} / \mathrm{ml}$ neutrophils.

Yeast cell phagocytosis assay. Phagocytosis assays were performed in parallel at two different PMNL concentrations: $7.5 \times 10^{5} / \mathrm{ml}$ and $15 \times 10^{5} / \mathrm{ml}$. A suspension of $6 \times 10^{7} / \mathrm{ml}$, heat killed yeast cells was used for the assays. The yeast suspension $(200 \mu \mathrm{l})$ was centrifuged and resuspended in $0.5 \%$ methylen blue solution. Two hundred $\mu \mathrm{l}$ of PBS and $200 \mu \mathrm{l}$ of RPMI cell culture medium containing $10 \%$ pooled human serum as opsonin collected from healthy subjects was added to the yeast suspension. After 10-min opsonisation either $100 \mu 1 \mathrm{PMNL}$ suspension plus $100 \mu \mathrm{l}$ RPMI, or $200 \mu 1$ of PMNL suspension was added and incubated for $1 \mathrm{~h}$ in a $37^{\circ} \mathrm{C}$ water bath. The incubation mixture contained $7.5 \times 10^{5}$ or $15 \times 10^{5} / \mathrm{ml}$ PMNLs and $15 \times 10^{6} / \mathrm{ml}$ opsonised yeast cells in a volume of $800 \mu \mathrm{l}$. At the end of the incubation, $200 \mu \mathrm{l}$ of $0.1 \mathrm{~mol} / \mathrm{l} \mathrm{Na-EDTA}$ was added to stop phagocytosis.

Microscopic evaluation of the assay: $10 \mu \mathrm{l}$ of the suspension was mixed with $7 \mu 11 \%$ eosin on a glass slide and covered by a glass cover plate. Internalised yeast cells in the living PMNLs remained blue, while dead PMNLs and yeast cells outside the PMNLs were stained red. Phagocytosis activity (FA), the percentage of PNMLs that performed phagocytosis, and phagocytosis index (FI), the number of yeast cells internalized by 100 PMNLs were calculated (23).

Effect of supernatants on yeast phagocytosis of polymorphonuclear leukocytes. Phagocytosis assays were performed with isolated healthy and trauma PMNLs at cell densities of $15 \times 10^{5} / \mathrm{ml}$. After $1 \mathrm{~h}$ of incubation the suspension was centrifuged (250 g, $5 \mathrm{~min}$ ). The supernatant was frozen and kept at $-18^{\circ} \mathrm{C}$ until further use. After thawing, $400 \mu 1$ supernatant was added to $200 \mu \mathrm{l}$ methylene blue stained yeast cells $\left(6 \times 10^{7} / \mathrm{ml}\right)$. Suspension $(200 \mu 1)$ of $6 \times 10^{6} / \mathrm{ml}$ healthy or trauma PMNLs was also added to the mixture and phagocytosis activity and index were evaluated after $1 \mathrm{~h}$ of incubation. Each time, parallel assays with $200 \mu \mathrm{l}$ PBS and $200 \mu$ l RPMI containing $10 \%$ pooled human serum instead of the $400 \mu \mathrm{l}$ supernatant were performed as controls.

Examination of PMNL phagocytosis with flow cytometry. The tests were carried out using the PhagoTest (Opregen Pharma) kit. Blood was taken from 6 healthy donors and 6 patients with severe tissue injury, 1 case with polytrauma, 3 with sepsis, and 2 underwent severe elective surgery, all between their 3rd and 10th day of their indicated severe status. All 
patients were treated at the intensive care unit. The samples were anticoagulated with heparin as prescribed in the operations manual of the kit. The blood was pipetted into three plastic tubes in the amounts of 200 (tube 1), 100 (tube 2) and $50 \mu 1$ (tube 3). The samples were centrifuged $\left(240 \mathrm{~g}, 5 \mathrm{~min}, 20^{\circ} \mathrm{C}\right)$. Half of the supernatant of the $200 \mu 1$ sample was removed and $50 \mu \mathrm{l}$ of RPMI was added to the $50 \mu 1$ sample, thus the tubes contained leukocytes at the ratio of 2:1:0.5. The tubes were vortexed and placed into ice-bath for $10 \mathrm{~min}$. Forty, 20 and $10 \mu \mathrm{l}$ of a suspension of $10 \% \mathrm{ml}$ heat killed, opsonized, FITC conjugated Esherichia coli were added, then the samples were placed into a $37^{\circ} \mathrm{C}$ water bath for $10 \mathrm{~min}$. Phagocytosis was terminated by putting the tubes into an ice-bath and icy quenching solution was added to quench the flourescence of the E. coli particles outside the leukocytes. After washing the samples twice ('washing solution', $250 \mathrm{~g}, 5 \mathrm{~min}, 4^{\circ} \mathrm{C}$ ), erythrocyte lysis and fixation ('lysing-fixation solution', for $20 \mathrm{~min}$, room temperature and washing once more), the cells were stained by 'DNA staining solution' $\left(10 \mathrm{~min}, 4^{\circ} \mathrm{C}\right)$.

The samples were evaluated with a Becton-Dickinson FACScan flow cytometer (excitation at $488 \mathrm{~nm}$ ). Each time 10000 cells in the gate set for positive DNA staining on the FL 2 (Phycoerythrin) detector were evaluated. A population of neutrophils showing rapid phagocytosis was detected during a series of previous measurements with increasing incubation times. It was found that there were cells already after $5 \mathrm{~min}$, which reached the maximum of their phagocytosis capacity, however, most of the PMNLs reached high bacterial engulfment later and it did not increase between 30 and 60 min. On the bases of five control measurements with incubation time of $60 \mathrm{~min}$ a gate - R2, was set so that at least $75 \%$ of the neutrophils fit inside, and this gate was used for the assessment of percentage of high FITC fluorescence high phagocytosis intensity PMNLs. The percentage of FITC positive cells and the mean channel value of FITC positive cells were also measured. PMN cells were identified on the side scatter - forward scatter dot plot by their size and granularity.

Statistical analysis. Data are presented with boxes indicating 25-75 percentiles, mean as a line in the box, 10-90 percentiles with error bars and outliers with dots. Differences were evaluated by analysis of variance (ANOVA) followed by the post-hoc multiple comparison according to the Dunnett's test for comparison of phagocytosis activity and phagocytosis index of PMNLs from multiple trauma patients compared to that of control PMNLs; with the Student's t-test for comparison of FI of PMNLs from acute pancreatitis patients and of control PMNLs; the Tukey's test to compare the E. coli phagocytosis tests of PMNLs of healthy subjects and patients with severe tissue injury. Data of the effects of supernatants on the phagocytosis of control and trauma PMNLs were evaluated with the Tukey's test and the Dunn's test. Differences were considered significant when $\mathrm{p}<0.05$.

\section{Results}

Comparison of leukocyte yeast phagocytosis of healthy subjects and patients with multiple trauma or acute pancreatitis dependence of phagocytosis on cell density. PMNLs separated

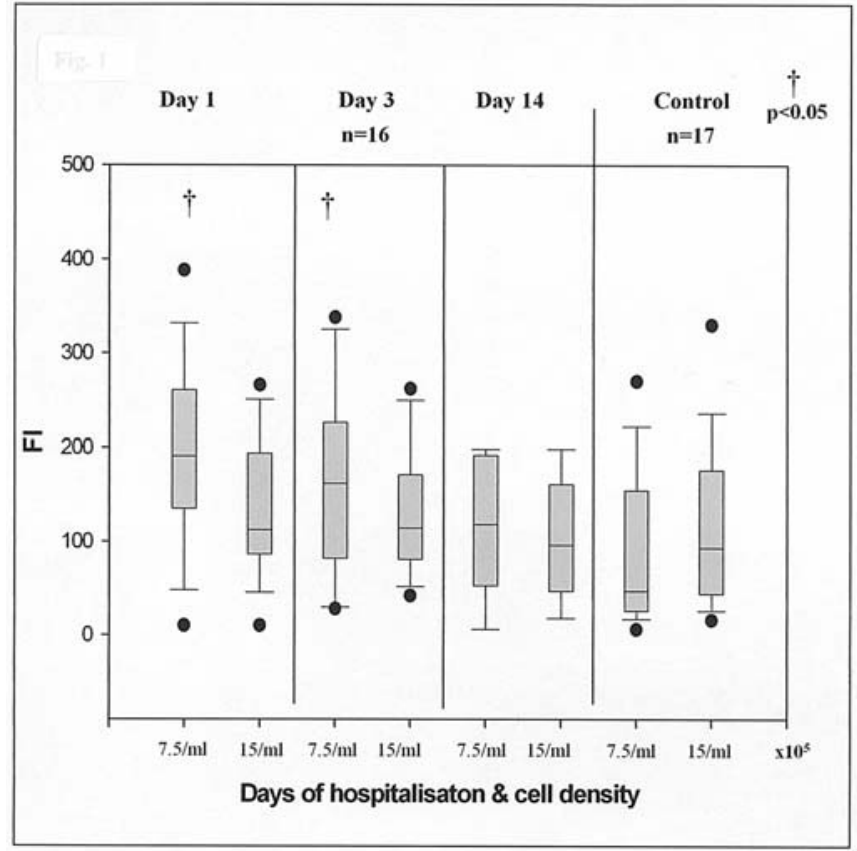

Figure 1. Change of phagocytosis index (FI) of PMNLs from multiple trauma patients $(n=16)$ compared to that of control PMNLs $(n=17)$. Data are presented with boxes indicating $25-75$ percentiles, mean as a line in the box, $10-90$ percentiles with error bars and outliers with dots. Difference was significant $(\mathrm{p}<0.05)$ between columns day 1 and 3 after trauma, $7.5 \times 10^{5} / \mathrm{ml}$ PMNLs vs. control $7.5 \times 10^{5} / \mathrm{ml}$ PMNLs. Statistical analysis was performed with two-way ANOVA followed by Dunnett's test.

from the blood of healthy subjects showed increased FI values at higher cell densities, but statistical significance could not be shown (Fig. 1).

FI of the multiple trauma group was significantly higher on the 1st and 3rd days of injury compared to the control if cell density was set to $7.5 \times 10^{5} / \mathrm{ml}$. FI at the higher cell density was also higher, but the difference was always less than that of the lower cell density assays, and statistical significance could not be shown (Fig. 1).

In the acute pancreatitis group, FI of the lower cell density assay on day 3 was found to be higher than that of the control, but statistical significance could not be shown (Fig. 2).

In both the multiple trauma and acute pancreatitis groups the FA values did not show any considerable changes throughout the studies.

Effects of supernatants of phagocytosis assays performed with PMNLs from healthy subjects and patients with multiple trauma on yeast phagocytosis of 'healthy' PMNLs. 'Healthy' supernatants in 7 cases increased and in 4 cases decreased, trauma supernatants of day one slightly decreased and trauma supernatants of day 3 and 14 uniformly and significantly decreased the FI values of control neutrophils (Fig. 3). Control supernatants significantly increased the phagocytosis of trauma PMNLs (Fig. 3).

Examination of E. coli phagocytosis of polymorphonuclear leukocytes (PMNL) by flow cytometry (Fig. 4). PMNLs both from healthy volunteers and patients with severe tissue injury 


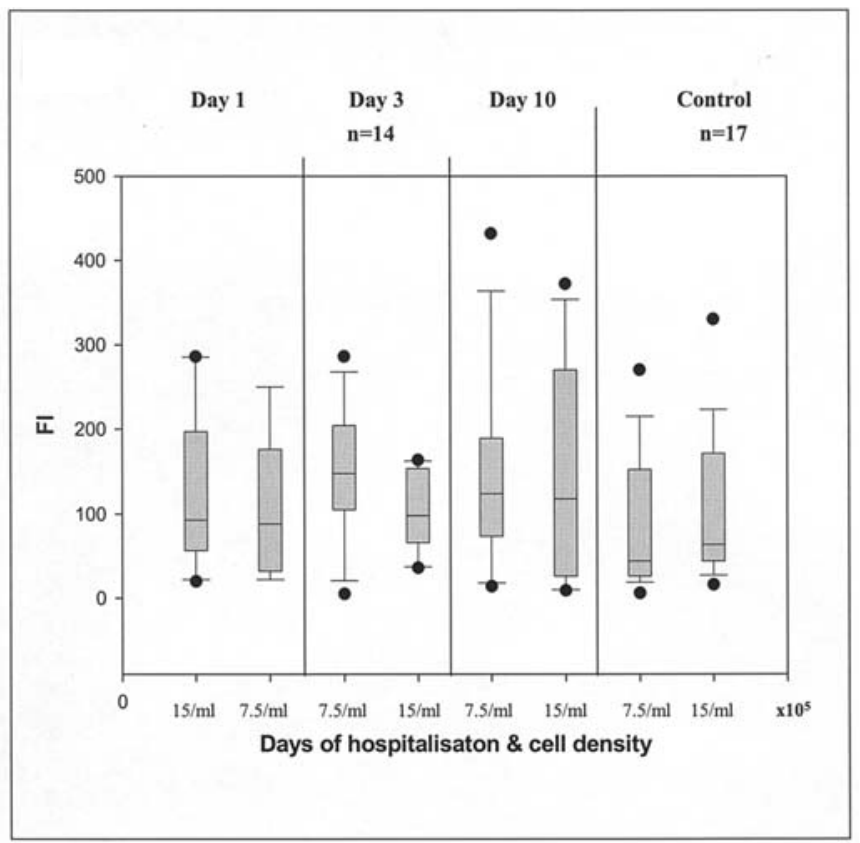

Figure 2. Change of FI of PMNLs from acute pancreatitis patients $(n=14)$ compared to that of control PMNLs $(n=17)$. Data are presented with boxes indicating 25-75 percentiles, mean as a line in the box, 10-90 percentiles with error bars and outliers with dots. No statistically significant difference can be shown among the groups.

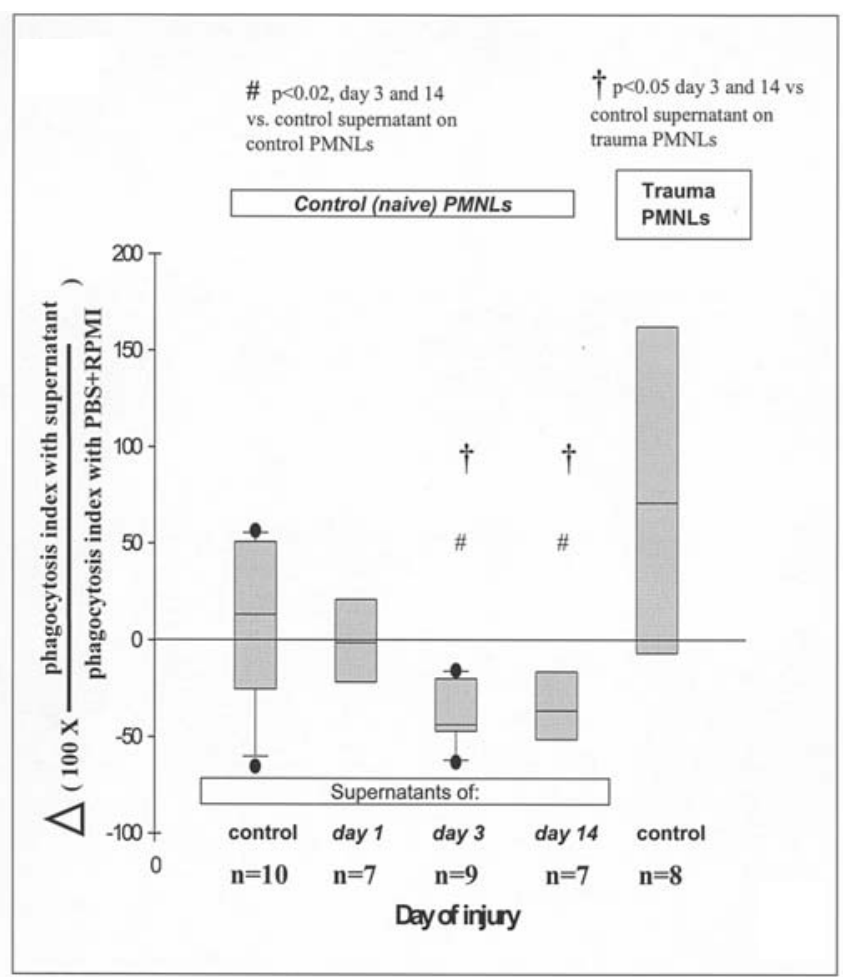

Figure 3. Effects of supernatants on the phagocytosis of control and trauma PMNLs. Effect of healthy control and trauma supernatants of day 1, 3 and 14 of hospitalisation on the FI of naive control PMNLs is expressed in percentage of FI of untreated parallels. Data are presented with boxes indicating 25-75 percentiles, mean as a line in the box, 10-90 percentiles with error bars and outliers with dots. Difference was found to be significant $(\mathrm{p}<0.05)$ comparing day 3 and 14 vs. control. Statistical analysis was performed using two-way ANOVA followed by Tukey's test. This figure also presents the result of effect of control supernatant on trauma PMNLs and it was significantly different from the effects of day 3 and 14 trauma supernatants on 'healthy' PMNLs. Statistical analysis was performed with two-way ANOVA followed by Dunn's test.

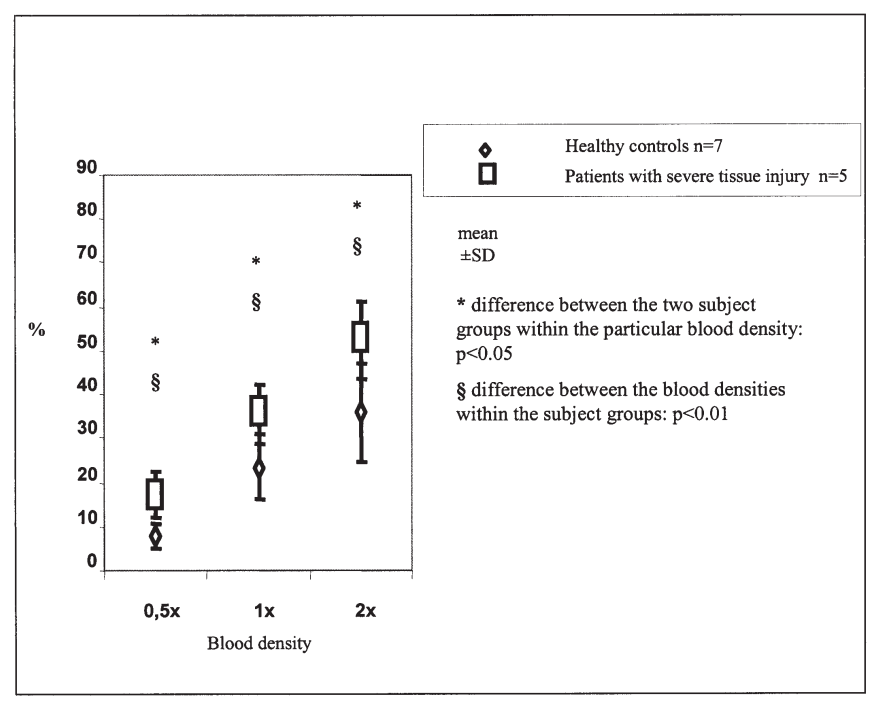

Figure 4. E. coli phagocytosis tests of PMNLs of healthy subjects and patients with severe tissue injury between the $3 \mathrm{rd}$ and 10th day of their indicated severe status. $\mathrm{X}$ axis indicates blood density, broken line with rhombi represents values of healthy control PMNLs, continuous line with rectangles represents values of tissue injury PMNLs. Y axis indicates the percentage of high fluorescence cells that performed rapid phagocytosis. Difference was statistically significant when comparing the values at the three different blood concentrations within the two investigational groups $(\mathrm{p} \leq 0.01)$. The percentages of high intensity PMNLs were significantly higher in cases of neutrophils from patients compared to healthy donors at each blood concentration. Statistical analysis was performed using two-way ANOVA followed by Tukey's test.

showed increasing $E$. coli phagocytosis with increasing cell densities. The differences were statistically significant between the two groups when comparing the values at the three different blood concentrations $(\mathrm{p} \leq 0.01)$.

\section{Discussion}

A high individual variability in yeast phagocytosis of PMNLs can be seen from the measurements in all cases (controls, trauma and acute pancreatitis). This variability can be due to the mixed gender of patients and the wide age range, as shown previously in examinations on endotoxic rat neutrophils and patient neutrophils $(31,32)$. Statistically significant effect of changing the cell density within the control, the trauma and the pancreatitis group cannot be shown between most of the groups, however, the following tendencies can be observed: a) PMNLs of healthy subjects facilitate each other's yeast phagocytosis when they are present in higher numbers, while b) this increase with growing cell density is absent when the cells are taken from patients with severe tissue injury. Injury of the organism increases the intensity of yeast phagocytosis greatly at the settings with the lower cell densities, however, this increase is absent at the settings with the higher cell densities.

From these results we conclude, that 'healthy' neutrophils may produce factors during the first hour of yeast phagocytosis assay, which facilitate their own function, and the more neutrophils are present, the more of these factors are released resulting in a stronger facilitating effect. On the other hand it seems possible, that PMNLs stimulated by tissue injury produce factors that inhibit yeast phagocytosis 
and the PMNLs can incorporate yeast in higher numbers only when their local cell concentration in the particular environment is low enough and the inhibitory factors cannot be produced in satisfactory amounts.

The theory about the facilitating and inhibitory factors led us to treat 'healthy' PMNLs with the supernatants of the phagocytosis assays of control and 'injured' neutrophils. These experiments clearly show the inhibitory effects of trauma supernatants on the phagocytosis of healthy neutrophils. On the other hand the facilitating effect of control supernatants on the 'trauma' PMNLs suggest that the decreased phagocytosis of these primed cells is not due to cytoskeletal changes, which might be irreversible, but to the humoral environment. Ayala et al (22) found trauma-induced suppression of several steps of antigen presentation by macrophages. They reported on the possible role of autocrine mechanisms (22). A similar phenomenon, that supernatants of control neutrophils in one part of the cases inhibited and in one part facilitated phagocytosis of control PMNLs, was described by Mózes (33). He investigated serum TNF- $\alpha$ levels of 10 healthy volunteers. The average serum levels of 4 subjects was $1490 \pm 185 \mathrm{U} / \mathrm{ml}$ while it was $402 \pm 320 \mathrm{U} / \mathrm{ml}$ in 6 others.

The examinations with $E$. coli phagocytosis gave different results. The percentage of rapidly phagocyting PMNLs showed an elevation with the increase of cell density, both in case of controls and tissue injury samples, but the 'injured' cells showed significantly higher values. It might be possible that the primed PMNLs start phagocytosis from a level of more increased activity than the naive ones. The production and release of the inhibitory factors may be time-consuming and the inhibitory effect develops only some time after the cells are activated by the presence of the yeast cells. This can party explain the difference in the results of the yeast and $E$. coli phagocytosis experiments. Further explanation may lay in the different receptor pathways and also in the size of particles to be incorporated, since yeast cells can be as large as a quarter to one third of a neutrophil acquiring more time, energy, and cell membrane for the phagocytosis compared to E. coli phagocytosis. Thirdly, the E. coli phagocytosis tests were in our case, and are usually being performed using anticoagulated whole blood, which may contain other substances that neutralize the effect of the released factors. The whole blood E. coli phagocytosis model therefore may present only a 'momentary' ability of phagocytosis in the blood, excluding the possibility of autocrine/paracrine mechanisms to develop. The blood is not the 'natural environment' of neutrophils for phagocytosis $(4,9,24,26)$. The yeast phagocytosis tests were in each case carried out in a humoral environment, the constitution of which was, apart of the factors released by the neutrophils themselves, well known.

The finding that the FA, that is the percentage of PMNL phagocyting yeast, did not change in any of the groups, suggests that always only an equal proportion of the neutrophils take an active part in yeast phagocytosis. Injury or the change in cell density only influence the phagocytosis of these cells. Bielefeldt and Babiuk (2) similarly found that bovine alveolar macrophages are composed of two subpopulations regarding reactive oxygen species production.

Previously a small number of studies were conducted to investigate the connection between cell functions and cell density. Ciz and Lojek (3) found increased chemiluminescence activity with rising cell density during the investigation of reactive oxygen species produced by murine splenocytes and bone marrow cells. Sud'ina et al (21) studied the dependence of neutrophil activation on cell density with human PMNLs in suspensions and adhered cells. They reported decreased superoxyde formation per cell and a decrease in the total amount of 5-lipoxygenase products per cell after various stimuli. Tanigawa et al (16) also reported an inverse relation between superoxide and hydrogen peroxide production and cell density in adherent human neutrophils. Raulf et al (20) described that human neutrophils released leukotrien D4dipeptidase in a cell number-dependent fashion. Peters et al (34) in their study on the autoregulation of human neutrophils found decreased reactive oxygen intermedier production per cell, attenuated arachidonic acid mobilisation and phospholipid metabolism in assays at higher cell densities. They concluded that multiple structural and functional aspects of PMNL activation response are modulated by the cell density.

The connection between cell density and phagocytosis has not been examined before, however, it is believed to be a major component of antimicrobial countermeasure. Our results correspond with the former observations and further emphasize the importance of the micro-environment of the cells studied.

The suppressive effect of the higher cell density in injury might also contribute to the neutrophil disfunction which can be observed in SIRS, MODS, and sepsis. The depression of the immune system in the early post-traumatic phase is already well understood $(5,14,15,19,33,35)$. Our results show that this period of low immune-reactivity might be prolonged even further.

\section{References}

1. Abraham E, Wunderink R, Silverman H, Perl TM, Nasraway S, Levy H, Bone R, Wenzel RP, Balk R, Allred R, et al: Efficacy and safety of monoclonal antibody to human tumor necrosis factor alpha in patients with sepsis syndrome. A randomized, controlled, double-blind, multicenter clinical trial. TNF-alpha MAb Sepsis Study Group. JAMA 273: 934-941, 1995.

2. Bielefeldt $\mathrm{OH}$ and Babiuk LA: In vitro generation of hydrogen peroxide and of superoxide anion by bovine polymorphonuclear neutrophilic granulocytes, blood monocytes, and alveolar macrophages. Inflammation 8: 251-275, 1984.

3. Ciz M and Lojek A: Kinetics of luminol-enhanced chemiluminescence induced in murine splenocytes and bone marrow cells by various stimulating agents. Folia Biol 39: 106-116, 1993.

4. Mullen PG, Windsor AC, Walsh CJ, Fowler AA III and Sugerman HJ: Tumor necrosis factor-alpha and interleukin-6 selectively regulate neutrophil function in vitro. J Surg Res 58: 124-130, 1995.

5. Demling R, La Londe C, Saldinger P and Knox J: Multipleorgan dysfunction in the surgical patient: pathophysiology, prevention, and treatment. Curr Probl Surg 30: 345-414, 1993.

6. Tanaka H, Ishikawa K, Nishino M, Shimazu T and Yoshioka T: Changes in granulocyte colony-stimulating factor concentration in patients with trauma and sepsis. J Trauma 40: 718-725, 1996.

7. Zallen G, Moore EE, Johnson JL, Tamura DY, Aiboshi J, Biffl WL and Silliman CC: Circulating postinjury neutrophils are primed for the release of proinflammatory cytokines. J Trauma 46: 42-48, 1999.

8. Zhang P, Xie M and Spitzer JA: Hepatic neutrophil sequestration in early sepsis: enhanced expression of adhesion molecules and phagocytic activity. Shock 2: 133-140, 1994. 
9. Wenisch C, Parschalk B, Patruta S, Brustbauer R and Graninger W: Effect of polyclonal immunoglobulins on neutrophil phagocytic capacity and reactive oxygen production in patients with gram-negative septicemia. Infection 27: 183-186, 1999.

10. Fossati G, Mazzucchelli I, Gritti D, Ricevuti G, Edwards SW, Moulding DA and Rossi ML: In vitro effects of GM-CSF on mature peripheral blood neutrophils. Int J Mol Med 1: 943-951, 1998.

11. Lipschitz DA, Udupa KB and Boxer LA: Evidence that microenvironmental factors account for the age-related decline in neutrophil function. Blood 70: 1131-1135, 1987.

12. Aguilar MM, Battistella FD, Owings JT, Olson SA and MacColl K: Post-traumatic lymphocyte response: a comparison between peripheral blood $\mathrm{T}$ cells and tissue $\mathrm{T}$ cells. J Trauma 45: 14-18, 1998.

13. Botha AJ, Moore FA, Moore EE, Peterson VM, Silliman CC and Goode AW: Sequential systemic platelet-activating factor and interleukin 8 primes neutrophils in patients with trauma at risk of multiple organ failure. Br J Surg 83: 1407-1412, 1996.

14. Guillou PJ: Biological variation in the development of sepsis after surgery or trauma. Lancet 342: 217-220, 1993.

15. Neidhart R, Keel M, Steckholzer U, Safret A, Ungethuem U, Trentz O and Ertel W: Relationship of interleukin-10 plasma levels to severity of injury and clinical outcome in injured patients. J Trauma 42: 863-870, 1997.

16. Tanigawa T, Kotake Y, Tanigawa M and Reinke LA: Mutual contact of adherent polymorphonuclear leukocytes inhibits their generation of superoxide. Free Radic Res 22: 361-373, 1995.

17. Belotsky S, Diamantstein L and Rubinstein E: Effect of allogeneic polymorphonuclear neutrophils on staphylococcal sepsis in mice. Eur Surg Res 27: 189-196, 1995.

18. Burger JA, Schoffel U, Sach M, Jacobs E, Kownatzki E, von Specht BU and Farthmann EH: Effects of peritonitis exudates on chemotaxis and phagocytosis of human neutrophils. Eur J Surg 161: 647-653, 1995.

19. Ogawa M: Acute pancreatitis and cytokines: 'second attack' by septic complication leads to organ failure. Pancreas 16: 312-315, 1998.

20. Raulf M, Konig W, Koller M and Stuning M: Release and functional characterization of the leukotriene D4-metabolizing enzyme (dipeptidase) from human polymorphonuclear leucocytes. Scand J Immunol 25: 305-313, 1987.

21. Sud'ina GF, Galkina SI, Margolis LB and Ullrich V: Dependence of neutrophil activation on cell density and adhesion. Cell Adhes Commun 5: 27-37, 1998.

22. Ayala A, Karr SM, Evans TA and Chaudry IH: Factors responsible for peritoneal granulocyte apoptosis during sepsis. J Surg Res 69: 67-75, 1997.

23. Stahl M, Reifenberg K and Losch U: Quantitative characterization of yeast cell incorporation in phagocytes: microscopic methods for differentiation between adherent and ingested particles. Zentralbl Veterinarmed B 36: 185-190, 1989.
24. Grutkoski PS, D'Amico R, Ayala A and Simms HH: Tumor necrosis factor-alpha-stimulated polymorphonuclear leukocytes suppress migration and bactericidal activity of polymorphonuclear leukocytes in a paracrine manner. Crit Care Med 30: 591-597, 2002.

25. Heller AR, Groth G, Heller SC, Breitkreutz R, Nebe T, Quintel M and Koch $\mathrm{T}$ : $\mathrm{N}$-acetylcysteine reduces respiratory burst but augments neutrophil phagocytosis in intensive care unit patients. Crit Care Med 29: 272-276, 2001.

26. Rothe G, Kellermann W and Valet G: Flow cytometric parameters of neutrophil function as early indicators of sepsis- or trauma-related pulmonary or cardiovascular organ failure. J Lab Clin Med 115: 52-61, 1990

27. Taylor JV, Gordon LE, Hall H, Heinzelmann M and Polk HC Jr: Differences between bacterial species shown by simultaneous assessment of neutrophil phagocytosis and generation of reactive oxygen intermediates in trauma patients. Arch Surg 134: $1222-1227,1999$.

28. Toth B, Schwacha MG, Kuebler JF, Bland KI, Wang P and Chaudrya IH: Gender dimorphism in neutrophil priming and activation following trauma-hemorrhagic shock. Int J Mol Med 11: 357-364, 2003.

29. Weiss M, Voglic S, Harms-Schirra B, Lorenz I, Lasch B, Dumon K, Gross-Weege W and Schneider EM: Effects of exogenous recombinant human granulocyte colony-stimulating factor (filgrastim, rhG-CSF) on neutrophils of critically ill patients with systemic inflammatory response syndrome depend on endogenous G-CSF plasma concentrations on admission. Intensive Care Med 29: 904-914, 2003.

30. Lipschitz DA, Udupa KB and Boxer LA: The role of calcium in the age-related decline of neutrophil function. Blood 71: 659-665, 1988 .

31. Wenisch C, Patruta S, Daxbock F, Krause R and Horl W: Effect of age on human neutrophil function. J Leukoc Biol 67: 40-45, 2000 .

32. Spitzer JA and Zhang P: Gender differences in neutrophil function and cytokine-induced neutrophil chemoattractant generation in endotoxic rats. Inflammation 20: 485-498, 1996.

33. Mózes T: The role of mediators of inflammation in endotoxin shock and post-traumatic infection. Thesis of dissertation Budapest, National Academy of Science, 1996.

34. Peters SP, Cerasoli F Jr, Albertine KH, Gee MH, Berd D and Ishihara Y: 'Autoregulation' of human neutrophil activation in vitro: regulation of phorbol myristate acetate-induced neutrophil activation by cell density. J Leukoc Biol 47: 457-474, 1990.

35. Cromack DT, Porras-Reyes B and Mustoe TA: Current concepts in wound healing: growth factor and macrophage interaction. J Trauma 30: S129-S133, 1990. 